\title{
Effects of $P$ implantation and post-implantation annealing on defect formation in $\mathrm{ZnO}$
}

\author{
Xiangjun Wang, Weimin Chen, F Ren, S Pearton and Irina Buyanova
}

\section{Linköping University Post Print}

N.B.: When citing this work, cite the original article.

Original Publication:

Xiangjun Wang, Weimin Chen, F Ren, $\mathrm{S}$ Pearton and Irina Buyanova, Effects of $\mathrm{P}$ implantation and post-implantation annealing on defect formation in $\mathrm{ZnO}, 2012$, Journal of Applied Physics, (111), 4, 043520.

http://dx.doi.org/10.1063/1.3687919

Copyright: American Institute of Physics (AIP) http://www.aip.org/

Postprint available at: Linköping University Electronic Press http://urn.kb.se/resolve?urn=urn:nbn:se:liu:diva-76194 


\title{
AIP Applied Physics
}

\section{Effects of P implantation and post-implantation annealing on defect formation in $\mathrm{ZnO}$}

\author{
X. J. Wang, W. M. Chen, F. Ren, S. Pearton, and I. A. Buyanova
}

Citation: J. Appl. Phys. 111, 043520 (2012); doi: 10.1063/1.3687919

View online: http://dx.doi.org/10.1063/1.3687919

View Table of Contents: http://jap.aip.org/resource/1/JAPIAU/v111/i4

Published by the American Institute of Physics.

\section{Related Articles}

High Si and Ge n-type doping of GaN doping - Limits and impact on stress

Appl. Phys. Lett. 100, 122104 (2012)

Nitrogen $\delta$-doping for band engineering of GaAs-related quantum structures

J. Appl. Phys. 111, 053512 (2012)

Tuning the electronic and magnetic properties of carbon-doped $\mathrm{ZnO}$ nanosheets: First-principles prediction J. Appl. Phys. 111, 044329 (2012)

Enhanced indirect ferromagnetic $\mathrm{p}-\mathrm{d}$ exchange coupling of $\mathrm{Mn}$ in oxygen rich $\mathrm{ZnO}: \mathrm{Mn}$ nanoparticles synthesized by wet chemical method

J. Appl. Phys. 111, 033503 (2012)

Lattice locations and properties of $\mathrm{Fe}$ in $\mathrm{Co} / \mathrm{Fe}$ co-implanted $\mathrm{ZnO}$

Appl. Phys. Lett. 100, 042109 (2012)

\section{Additional information on J. Appl. Phys.}

Journal Homepage: http://jap.aip.org/

Journal Information: http://jap.aip.org/about/about_the_journal

Top downloads: http://jap.aip.org/features/most_downloaded

Information for Authors: http://jap.aip.org/authors

\section{ADVERTISEMENT}
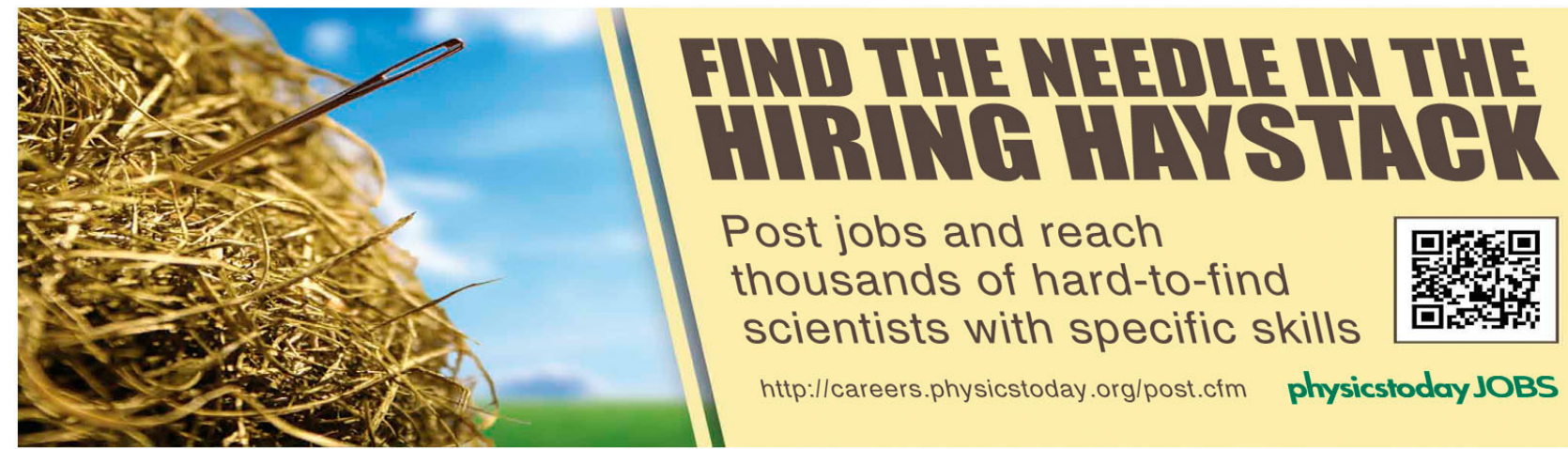


\title{
Effects of $P$ implantation and post-implantation annealing on defect formation in $\mathrm{ZnO}$
}

\author{
X. J. Wang, ${ }^{1,2}$ W. M. Chen, ${ }^{1}$ F. Ren, ${ }^{3}$ S. Pearton, ${ }^{4}$ and I. A. Buyanova ${ }^{1, a)}$ \\ ${ }^{1}$ Department of Physics, Chemistry and Biology, Linköping University, Linköping S-581 83, Sweden \\ ${ }^{2}$ Chinese Academy of Sciences, National Laboratory for Infrared Physics, Shanghai Institute of Technical \\ Physics, Shanghai 200083, Peoples Republic of China \\ ${ }^{3}$ Department of Chemical Engineering, University of Florida, Gainesville, Florida 32611, USA \\ ${ }^{4}$ Department of Materials Science and Engineering, University of Florida, Gainesville, Florida 32611, USA
}

(Received 23 November 2011; accepted 30 January 2012; published online 27 February 2012)

\begin{abstract}
Photoluminescence (PL) and optically detected magnetic resonance (ODMR) techniques are utilized to examine the effects of $\mathrm{P}$ implantation and post-implantation annealing on defect formation in $\mathrm{ZnO}$ single crystals. From ODMR, the main defects created by ion implantation include oxygen and zinc vacancies as a well as a deep donor labeled as PD. The formation of the PD defect is likely promoted by the presence of $\mathrm{P}$ as it could only be detected in the $\mathrm{P}$-containing $\mathrm{ZnO}$. The $\mathrm{V}_{\mathrm{O}}$ and $\mathrm{PD}$ centers are found to exhibit low thermal stability and can be annealed out at $800^{\circ} \mathrm{C}$. On the other hand, a new set of defects, such as Z, T, and $\mathrm{D}^{*}$ centers, is detected after annealing. Based on measured spectral dependences of the ODMR signals, the $\mathrm{V}_{\mathrm{O}}, \mathrm{V}_{\mathrm{Zn}}$, and $\mathrm{PD}$ centers are shown to participate in spin-dependent recombination processes related to red emissions, whereas the $\mathrm{Z}, \mathrm{T}$, and $\mathrm{D}^{*}$ centers are involved in radiative recombination over a wide spectral range of $1.55-2.5 \mathrm{eV}$. From the PL measurements, combined effects of implantation and annealing also lead to appearance of a new PL band peaking at $\sim 3.156 \mathrm{eV}$, likely due to donor-acceptor-pair recombination. The formation of the involved deep acceptor is concluded to be facilitated by the presence of P. (C) 2012 American Institute of Physics. [http://dx.doi.org/10.1063/1.3687919]
\end{abstract}

\section{INTRODUCTION}

In recent years $\mathrm{ZnO}$ has gained increasing attention worldwide as a promising electronic material for a wide variety of applications such as in biological and gas sensors, transparent electronics, solar cells, and spintronics. ${ }^{1-5}$ Owing to a direct and wide bandgap $(\sim 3.3 \mathrm{eV}$ at room temperature) and a large exciton binding energy $(\sim 60 \mathrm{meV}), \mathrm{ZnO}$ is also considered as a strong candidate for UV light emitters and solid-state white lighting. However, widespread exploitation of this material in device applications has been hindered by difficulties in controlling its electrical conductivity and, particularly, in realizing p-type material. Based on simple valence electron arguments, a natural approach for p-type doping is to use group V elements such as phosphorous. Several groups have indeed reported p-type conductivity in phosphorous-doped $\mathrm{ZnO}$ fabricated by sputtering, ${ }^{6,7}$ molecular beam epitaxy (MBE), ${ }^{8}$ pulse laser deposition (PLD), ${ }^{9}$ metal organic chemical vapor deposition (MOCVD), ${ }^{10}$ and atomic layer deposition (ALD). ${ }^{11}$ However, reliably and reproducibly achieving $p$-type $\mathrm{ZnO}$ material by in situ doping with $\mathrm{P}$ during the growth still remains a challenge since $\mathrm{P}$-doped $\mathrm{ZnO}$ thin films grown by the same techniques are also often semi-insulating ${ }^{12}$ or even $n$-type conductive. ${ }^{13}$ The probable reasons for these difficulties include low P solubility, self-compensation as well as presence of other grown-in defects that affect its electrical activity. Indeed, the first-principles pseudopotential calculations ${ }^{14,15}$ have shown that electrical activity of $\mathrm{P}$ largely depends on its local con-

${ }^{a)}$ Electronic mail: irb@ifm.liu.se. figuration and surrounding in the crystal lattice. $\mathrm{P}$ is predicted to act as a deep acceptor when simply substituting an $\mathrm{O}$ atom $\left(\mathrm{P}_{\mathrm{O}}\right)$. On the other hand, it may introduce a shallow acceptor state at $\mathrm{E}_{\mathrm{v}}+150 \mathrm{meV}$ (Ref. 16) for a $\mathrm{P}_{\mathrm{Zn}}-2 \mathrm{~V}_{\mathrm{Zn}}$ complex (i.e., when $\mathrm{P}$ occupies a $\mathrm{Zn}$ site and forms a complex with two nearby $\mathrm{Zn}$ vacancies).

An alternative technique that in principle allows one to incorporate dopants in a controllable manner is ion implantation. Several attempts to achieve p-type doping by P implantation have been reported ${ }^{17,18}$ but have only succeeded to attain a significant reduction in the electron concentrations in the implanted material. Here, the likely problem is compensation of the acceptors by various defects that are commonly created due to collisions of implanted ions with lattice atoms. These defects could also affect activation of the dopants during subsequent annealing. While a number of previous studies ${ }^{19-21}$ were devoted to characterization of defects created by ion implantation or electron bombardment, only some of them focused on $\mathrm{P}$-implanted $\mathrm{ZnO}$. Vaithianathan et al. ${ }^{17}$ have observed substantial changes in photoluminescence (PL) spectra of $\mathrm{ZnO}$ depending on $\mathrm{P}$ dose and also subsequent annealing, which indicated significant changes in defect compositions. Chen et al. ${ }^{18}$ have shown formation of zinc vacancies and related clusters using positron annihilation spectroscopy. They have also suggested implantation-induced creation of $\mathrm{O}$ vacancies based on the observed enhancement of the broad Raman line at $575 \mathrm{~cm}^{-1}$ after $\mathrm{P}$ implantation. The actual chemical origin of the monitored defects remains questionable, however, as Raman spectroscopy does not provide defect identification unless isotope effect is closely examined. In fact the same Raman mode has previously been 
attributed $^{22}$ to the density of phonon states (DOPS) of the high-energy phonon branch activated by lattice disorder.

A suitable method for investigations of defects origin is optically detected magnetic resonance (ODMR) ${ }^{23}$ Though this method has been successfully used to identify defects in electron-irradiated ${ }^{20,24}$ and as-grown ${ }^{25} \mathrm{ZnO}$, it has not been applied so far to ion implanted materials. In this work we employ this technique and complementary PL measurements to perform comprehensive characterizations of defects formed in $\mathrm{ZnO}$ as a result of $\mathrm{P}$ implantation and also subsequent thermal annealing.

\section{EXPERIMENTAL}

The investigated samples were (0001)-oriented undoped bulk $\mathrm{ZnO}$ single crystals from Cermet Inc. Ion implantation was performed at $300 \mathrm{~K}$ in a non-channeling direction with $\mathrm{P}+$ ions of energy $30,60,120$, and $200 \mathrm{keV}$ and doses of $6 \times$ $10^{12}, 1.2 \times 10^{13}, 2.5 \times 10^{13}$, and $5 \times 10^{13} \mathrm{~cm}^{-2}$, respectively, to create an approximately uniform concentration profile. The overall thickness of the implanted layers was about $300 \mathrm{~nm}$. Following implantation, some of the samples were annealed by rapid thermal annealing (RTA) at $800^{\circ} \mathrm{C}$ for 2 min under a flowing $\mathrm{O}_{2}$ or $\mathrm{N}_{2}$ ambient. This annealing temperature was determined from previous experiments to be the optimum in terms of removing implantation damage at these doses while avoiding preferential loss of oxygen from the $\mathrm{ZnO}$ surface. In both ambients, we also placed the $\mathrm{ZnO}$ samples face down on sacrificial $\mathrm{ZnO}$ substrates to minimize surface degradation. PL and ODMR measurements were carried out at $5 \mathrm{~K}$ using the 351-nm line from an $\mathrm{Ar}^{+}$ion laser as an excitation source. PL signals were collected by a chargecoupled-device (CCD) assembled with a grating monochromator. ODMR measurements were performed at microwave (MW) frequencies of $9.14-9.28 \mathrm{GHz}$ and a power of 1-200 mW using on/off microwave field modulation. ODMR spectra were obtained as a MW-induced change of PL intensity detected by a Si detector when monitoring PL emissions within the visible spectral range, in a sweeping magnetic field.

\section{RESULTS AND DISCUSSION}

\section{A. Photoluminescence}

Figure 1 summarizes the effects of $\mathrm{P}$ ion implantation and annealing on PL spectra measured from the investigated samples, whereas the inset in Fig. 1 shows a close-up of the PL spectra within the near-band-edge (NBE) spectral range. Typical for undoped $\mathrm{ZnO}$, the PL spectrum from the untreated sample exhibits a rich structure within the NBE range due to several sharp bound exciton lines (labeled ${ }^{26}$ as $\mathrm{I}_{4}, \mathrm{I}_{6} \mathrm{I}_{7}$, and $\mathrm{I}_{9}$ in the inset in Fig. 1), their corresponding two-electron-satellite (TES) transitions as well as donor-acceptor-pair (DAP) emissions. These transitions are accompanied by their longitudinal optical (LO) phonon replica labeled as DX-LO, TESLO, and DAP-LO. The spectrum also contains the so-called DBX-line, previously assigned to deeply bound excitons at structural defects. ${ }^{26}$

All these emissions are drastically quenched after P implantation, which evidences degradation of optical quality as

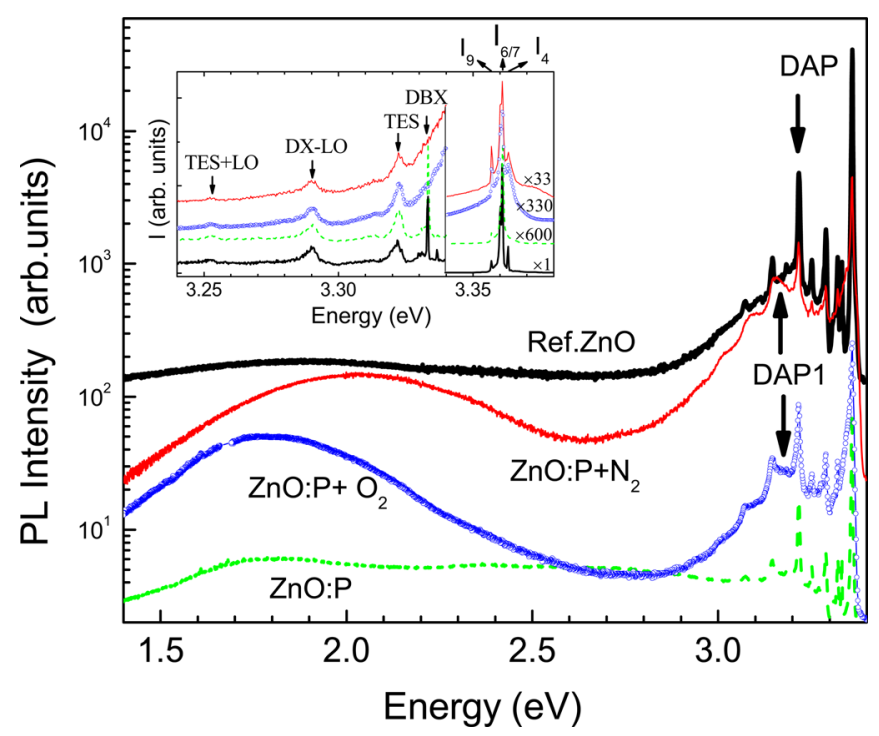

FIG. 1. (Color online) PL spectra measured at $5 \mathrm{~K}$ from the as-grown (labeled as Ref. $\mathrm{ZnO}$ ), P-implanted (ZnO:P), as well as P-implanted $\mathrm{ZnO}$ samples after annealing in $\mathrm{N}_{2}\left(\mathrm{ZnO}: \mathrm{P}+\mathrm{N}_{2}\right)$ and $\mathrm{O} 2\left(\mathrm{ZnO}: \mathrm{P}+\mathrm{O}_{2}\right)$ ambient. The spectra are displayed in the logarithmic-linear $(\mathrm{y}-\mathrm{x})$ scale. The inset shows a close-up of the spectra within the near-band-edge spectral range, which is displayed in the linear-linear scale and is offset vertically, for clarity.

a result of ion bombardment. Annealing, on the other hand, leads to a partial recovery of the PL intensity that is especially pronounced when RTA was performed in $\mathrm{N}_{2}$ ambient. Simultaneously, several new emissions appear in the spectra. First of all, these include a PL peak at $\sim 3.156 \mathrm{eV}$ (labeled as DAP1 in Fig. 1) and its LO-phonon replica spaced by about $72 \mathrm{meV}$. The contribution of this emission is somewhat stronger for the sample annealed in $\mathrm{N}_{2}$ (to be referred below as $\mathrm{ZnO}: \mathrm{P}+\mathrm{N}_{2}$ ), although it is also present in the PL spectrum from the P-implanted $\mathrm{ZnO}$ after annealing in $\mathrm{O}_{2}$ ambient (to be referred below as $\mathrm{ZnO}: \mathrm{P}+\mathrm{O}_{2}$ ). A similar PL peak at $\sim 3.11 \mathrm{eV}$ has been previously reported by Allenic et al. ${ }^{9}$ in P-doped $\mathrm{ZnO}$ epitaxial films and was attributed to transitions between a shallow donor and a deep $\left(\mathrm{E}_{\mathrm{v}}+0.34 \mathrm{eV}\right)$ acceptor induced by phosphorus doping. In our samples, this peak could only be detected in the $\mathrm{P}$ implanted $\mathrm{ZnO}$, but was not observed in the samples co-implanted with $\mathrm{N}$ and $\mathrm{O}$ or $\mathrm{N}$ and $\mathrm{Zn}$ ions. Though based on these observations, it is tempting to assume that the formed deep acceptor directly involves a $\mathrm{P}$ atom, we cannot rule out the possibility that it is unrelated to $\mathrm{P}$ but its formation is promoted by the presence of phosphorous.

In addition to the 3.156-eV emission, $\mathrm{P}$ implantation and subsequent annealing also lead to appearance of several broad PL bands of defect origin with peak positions at $\sim 1.80 \mathrm{eV}, \sim 2.05 \mathrm{eV}$ and $\sim 2.75 \mathrm{eV}$. Intensities of these emissions critically depend on annealing conditions. For example, the 2.75-eV PL band is only observed in the P-implanted $\mathrm{ZnO}$ prior to RTA whereas the $\sim 1.80-\mathrm{eV}$ PL band is most pronounced after annealing in $\mathrm{O}_{2}$ ambient, consistent with earlier results of Ref. 18. The $1.80-\mathrm{eV}$ band is replaced, however, by the $2.05 \mathrm{eV}$ emission when RTA is performed in $\mathrm{N}_{2}$ gas. The observed changes in the PL spectra imply significant modifications in the defect properties of the investigated samples upon implantation and annealing. 


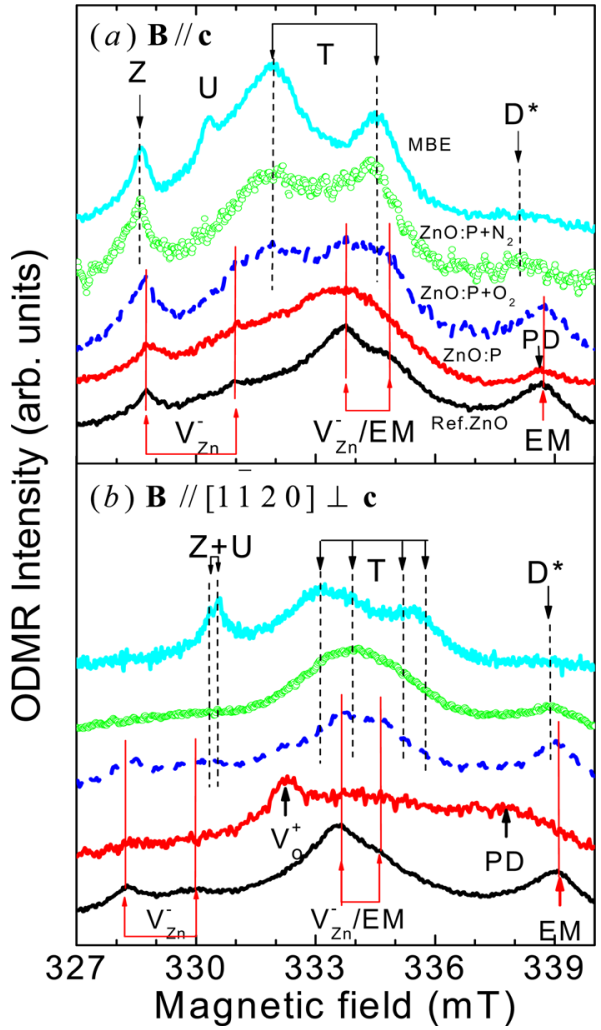

FIG. 2. (Color online) ODMR spectra measured at $4 \mathrm{~K}$ from the investigated samples with magnetic fields either parallel (a) or perpendicular (b) to the c-axis. Also shown are the ODMR spectra from MBE-grown $\mathrm{ZnO}$ with pronounced signals from $\mathrm{Z}, \mathrm{T}$, and $\mathrm{D}^{*}$ centers (the upmost curves). The spectra were measured under a MW power of $100 \mathrm{~mW}$.

\section{B. ODMR}

\section{Spin-resonance signatures of defects}

To further understand the effects of $\mathrm{P}$ implantation on the defect formation in $\mathrm{ZnO}$ we have performed ODMR measurements. This technique allows one to trace various paramagnetic defects that are active in recombination processes since each defect often possesses a unique set of spin Hamiltonian parameters, which could be used as its fingerprint.

Representative ODMR spectra from the investigated samples are summarized in Fig. 2. All spectra were obtained by monitoring the defect-related broad PL emissions-see

TABLE I. Summary of the spin Hamilton parameters determined for the defects studied in this work. For the axial centers, the parallel direction (//) corresponds to the principal axis of the defects, which coincides with the $\mathbf{c}$ axis of $\mathrm{ZnO}$. For the non-axial centers, the $\mathrm{z}$ and $\mathrm{x}$ axes lie in a $\{11 \overline{2} 0\}$ plane, and $\theta$ is the angle between the $\mathrm{z}$ and $\mathbf{c}$ axes.

\begin{tabular}{lccccccccc}
\hline \hline \multicolumn{3}{c}{ Axial } & \multicolumn{7}{c}{ Non-axial } \\
\hline Center & $\mathrm{S}$ & $\mathrm{g} \|$ & $\mathrm{g}_{\perp}$ & $\mathrm{g}_{\mathrm{x}}$ & $\mathrm{g}_{\mathrm{y}}$ & $\mathrm{g}_{\mathrm{z}}$ & $\theta(\mathrm{deg})$ & $\mathrm{D}(\mathrm{MHz})$ & $\mathrm{E}(\mathrm{MHz})$ \\
\hline $\mathrm{EM}$ & $1 / 2$ & 1.957 & 1.9551 & & & & & \\
$\mathrm{D}^{*}$ & $1 / 2$ & 1.9605 & 1.9565 & & & & & & \\
$\mathrm{PD}$ & $1 / 2$ & 1.957 & 1.964 & & & & & & \\
$\mathrm{~T}$ & 1 & \multicolumn{1}{c}{1.9812} & 1.9814 & 1.9901 & 15.7 & 36.27 & -26.01 \\
$\mathrm{Z}$ & $1 / 2$ & \multicolumn{1}{c}{2.006} & 2.006 & 2.02 & 20 & & \\
$\mathrm{~V}_{\mathrm{O}}{ }^{+}$ & $1 / 2$ & 1.9945 & 1.9960 & & & & & & \\
$\mathrm{~V}_{\mathrm{Zn}}{ }^{-}$ & $1 / 2$ & 2.0024 & 2.0193 & 2.0173 & 2.0183 & 2.0028 & 110.75 & \\
\hline \hline
\end{tabular}

Fig. 1. The ODMR spectra of the reference (i.e., not implanted) $\mathrm{ZnO}$ are shown by the lowest curves in Figs. 2(a) and 2(b) and contain several signals. Field positions of these signals are found to depend on the angle $\alpha$ between the directions of an applied magnetic field $\mathbf{B}$ and the crystallographic c-axis c. This can be seen, e.g., from comparison of the spectra measured with $\mathbf{B} \| \mathbf{c}$ and $\mathbf{B} \|[1 \overline{1} 20] \perp \mathbf{c}$, as shown in Figs. 2(a) and 2(b), respectively. Spin-Hamiltonian parameters of the involved defects, such as g-tensor $(\boldsymbol{g})$ and effective electron spin (S), can be obtained from the performed analysis ${ }^{25}$ of the measured angular dependences by using the following spin-Hamiltonian

$$
H=\mu_{B} \boldsymbol{B} \cdot \boldsymbol{g} \cdot \boldsymbol{S} .
$$

They are summarized in Table I. Here $\mu_{\mathrm{B}}$ is the Bohr magneton. Based on the obtained parameters, the signals can be ascribed to an effective-mass (EM) donor, a negatively charged $\mathrm{Zn}$ vacancy $\left(\mathrm{V}_{\mathrm{Zn}}{ }^{-}\right)$, as well as an exchange-coupled pair of the EM donor and $\mathrm{V}_{\mathrm{Zn}}{ }^{-}$acceptor, as well documented in the literature. ${ }^{24}$ The $\mathrm{V}_{\mathrm{Zn}}{ }^{-}$signal has two components, i.e., from axial and non-axial centers, which allows one to easily distinguish it from other ODMR signals, such as the Z-signal to be discussed hereafter.

ODMR spectra significantly change after the implantation (shown by the second curves (red online) from the bottom in Figs. 2(a) and 2(b). In addition to $\mathrm{V}_{\mathrm{Zn}}{ }^{-}$, the spectra now contain new signals labeled as $\mathrm{V}_{\mathrm{O}}^{+}$and $\mathrm{PD}$, which becomes most apparent in the spectra measured with $\mathbf{B} \perp \mathbf{c}-$ see Fig. 2(b). Their spin Hamiltonian parameters were obtained by simulating angular variations of the related signals with the aid of the spin Hamiltonian (Eq. (1)) and are also summarized in Table I. It is found that the $\mathrm{V}_{\mathrm{O}}{ }^{+}$signal arises from an axial center with $\mathrm{S}=1 / 2, g_{\|}=1.9945$ and $g_{\perp}=1.9960$. The obtained spin Hamiltonian parameters are identical to those for the positively charged oxygen vacancy $\left(\mathrm{V}_{\mathrm{O}}{ }^{+}\right)$in electronirradiated $\mathrm{ZnO},{ }^{20,27}$ which unambiguously proves formation of these defects as a result of $\mathrm{P}$ implantation. As to the PD signal, its spin Hamiltonian parameters $\mathrm{S}=1 / 2, g_{\|}=1.957$, and $g_{\perp}=1.964$, are close to the values reported for donors in $\mathrm{ZnO}$ suggesting the donor origin of this signal.

Both $\mathrm{V}_{\mathrm{O}}{ }^{+}$and PD signals are found to be strongly suppressed by RTA irrespective of the gas atmosphere (i.e., $\mathrm{N}_{2}$ or $\mathrm{O}_{2}$ ) during the annealing-see Fig. 2. The observed low thermal stability of $\mathrm{V}_{\mathrm{O}}$ is consistent with the known thermal annealing behavior of this center. ${ }^{20,25}$ Simultaneously, several new signals labeled as $\mathrm{Z}, \mathrm{D}^{*}$, and $\mathrm{T}$ appear in the spectra. These signals are the most pronounced when annealing was performed in $\mathrm{N}_{2}$ ambient as can be seen from Fig. 2, where the corresponding spectra are shown by the green open circles. The notations of the new signals are chosen based on their close resemblance to the signals with the same labels detected previously from MBE-grown $\mathrm{ZnO}^{28,29}$ To demonstrate this similarity, we have included in Fig. 2 representative ODMR spectra from an undoped $\mathrm{ZnO}$ epilayer grown by MBE under O-rich conditions (the topmost curves in Figs. 2(a) and 2(b)). The $\mathrm{D}^{*}$ signal belongs to a donor center with axial symmetry $\left(\mathrm{C}_{3 \mathrm{v}}\right)$ and $S=1 / 2$. Though the field position of this signal practically coincides with that from the EM 
donor when $\mathbf{B} \perp \mathbf{c}$ (see Fig. 2(b)), it is more anisotropic than EM, which could easily be seen by comparing positions of these donor signals when $\mathbf{B} \| \mathbf{c}$ (Fig. 2(a)). This implies different origin for the two donors. The $\mathrm{Z}$ center is an axial acceptor with $\mathbf{S}=1 / 2{ }^{28,29}$ Its principal axis, however, is tilted by about $20^{\circ}$ away from the c-axis in the $\{11 \overline{2} 0\}$ plane, which is different from the previously discussed axial defects. For the orientations of magnetic fields as chosen in Fig. 2, this signal can be distinguished from $\mathrm{V}_{\mathrm{Zn}}{ }^{-}$based on (i) a slightly different position as compared with that for the non-axial $\mathrm{V}_{\mathrm{Zn}}{ }^{-}$when $\mathbf{B} \| \mathbf{c}$ - see Fig. 2(a); (ii) a lack of the high field component from the axial $\mathrm{V}_{\mathrm{Zn}}{ }^{-}$; and (iii) a low signal intensity ${ }^{28}$ when $\mathbf{B} \perp$ c. (A strong ODMR line at around $330.5 \mathrm{mT}$ observed in the MBE-grown $\mathrm{ZnO}$ (Fig. 2(b)) is mainly due to the socalled U-center, ${ }^{28}$ which is not detected in the implanted samples.) As to the T center, it is an anisotropic complex defect that is composed of a close exchange-coupled pair of the $\mathrm{D}^{*}$ donor and $\mathrm{Z}$ acceptor forming a spin triplet $(\mathbf{S}=1)$ state. In order to adequately describe the angular dependence of this signal the spin-Hamiltonian should be modified as; ${ }^{28,29}$

$$
H=\mu_{B} \boldsymbol{B} \cdot \boldsymbol{g} \cdot \boldsymbol{S}+D\left[S_{z}^{2}-\frac{1}{3} S(S+1)\right]+E\left(S_{x}^{2}-S_{y}^{2}\right),
$$

where $D$ and $E$ are the zero-field splitting parameters. All spin-Hamiltonian parameters for the $\mathrm{D}^{*}, \mathrm{Z}$, and $\mathrm{T}$ centers are given in Table I. Due to anisotropy of the T center, its ODMR spectra are known to exhibit a complicated pattern when the magnetic field is tilted away from the high symmetry c-axis. As a result, distinctly different ODMR spectra are observed in magnetic fields that are oriented perpendicular to the $\mathbf{c}$-axis but lie in two inequivalent axes, e.g., for $\mathbf{B} \|[1 \overline{1} 20]$ or $\mathbf{B} \|[10 \overline{1} 0]$, respectively. Therefore, to confirm the formation of the T-center in $\mathrm{ZnO}: \mathrm{P}+\mathrm{N}_{2}$, we have also performed the ODMR measurements with $\mathbf{B} \|[10 \overline{1} 0] \perp \mathbf{c}$. The corresponding spectrum is presented in Fig. 3 together with the ODMR spectra measured with $\mathbf{B} \|[1 \overline{1} 20] \perp \mathbf{c}$ and $\mathbf{B} \| \mathbf{c}$, for a direct comparison. The thin (blue online) curves in Fig. 3 represent the experimental spectra whereas the simulated spectra for the $\mathrm{T}$ center using the spin-Hamiltonian parameters given in Table I are shown by the thick (red online) lines. A good agreement between the experimental data and simulations is achieved, ${ }^{30}$ confirming the suggested assignment of the ODMR signals.

Based on the ODMR spectra shown in Fig. 2, the Z, T, and $\mathrm{D}^{*}$ centers are also formed in $\mathrm{ZnO}: \mathrm{P}+\mathrm{O}_{2}$, where they coexist with the $\mathrm{V}_{\mathrm{Zn}}{ }^{-}, \mathrm{V}_{\mathrm{Zn}}{ }^{-} / \mathrm{EM}$, and EM centers. This can be clearly seen after subtracting contributions from the latter signals from the measured spectrum. The result of such subtraction, i.e., the difference between the ODMR spectra measured from the $\mathrm{ZnO}: \mathrm{P}+\mathrm{O}_{2}$ (curve I) and reference sample (curve II), is shown by the curve III in Fig. 4. The obtained spectrum is very similar to that measured from $\mathrm{ZnO}: \mathrm{P}+\mathrm{N}_{2}$ (curve IV), i.e., it contains the $\mathrm{Z}$, $\mathrm{T}$, and $\mathrm{D}^{*}$ signals.

\section{Defect involvement in radiative recombination}

All detected ODMR signals have a positive sign. This means that microwave induced transitions between spin-split sublevels of the defect centers lead to an enhancement of the

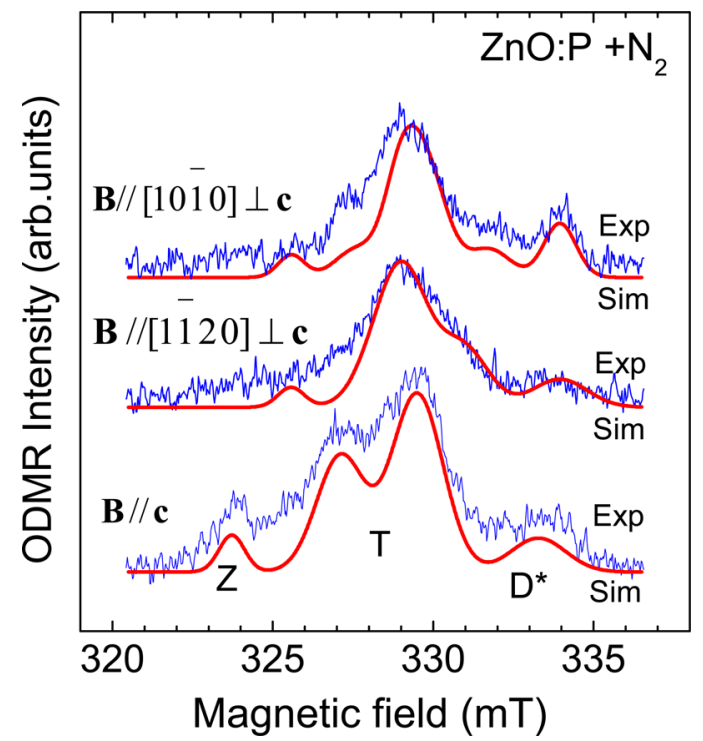

FIG. 3. (Color online) ODMR spectra [the thin (blue online) lines] measured from the P-implanted $\mathrm{ZnO}$ after annealing in $\mathrm{N}_{2}\left(\mathrm{ZnO}: \mathrm{P}+\mathrm{N}_{2}\right)$ with the specified magnetic field directions. The spectra were measured under a MW power of $1 \mathrm{~mW}$. The (thick (red online) lines represent simulated ODMR spectra of the Z, T, and $\mathrm{D} *$ signals using the spin-Hamiltonian parameters given in Table I. A weak background signal of a Gaussian line shape with a g-value of $\sim 1.985$ of unknown origin was also included in the simulated spectra, to improve agreement with the experimental data.

monitored emission, i.e., acceleration of the corresponding radiative recombination transitions. This is typically observed when a defect directly participates in the monitored recombination process and provides the opportunity to determine the spectral range of PL associated with this specific defect. For these purposes, we examined spectral dependences of the revealed ODMR signals. The latter was done by detecting ODMR spectra within several spectral windows

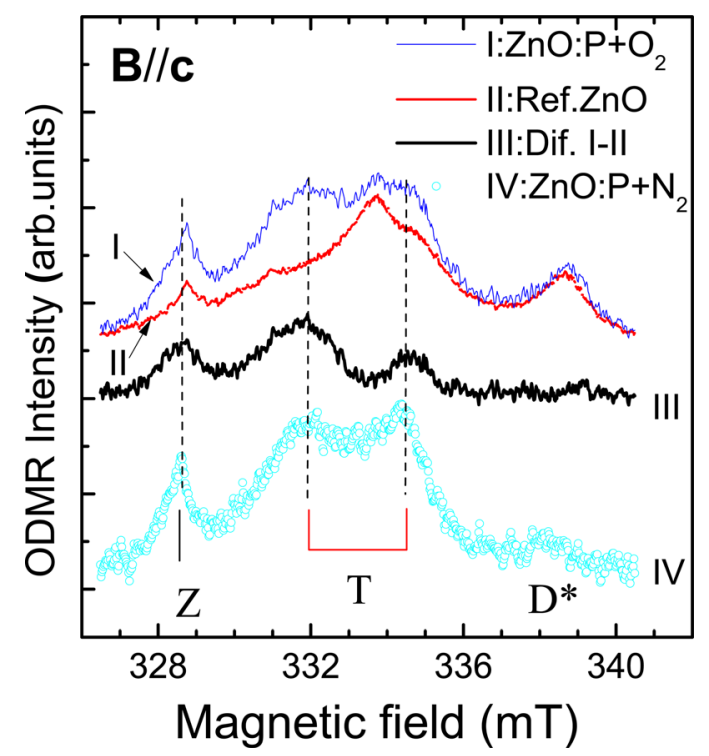

FIG. 4. (Color online) ODMR spectrum measured with $\mathbf{B} \| \mathbf{c}$ from the $\mathrm{P}$-implanted $\mathrm{ZnO}$ after annealing in $\mathrm{O}_{2}\left(\mathrm{ZnO}: \mathrm{P}+\mathrm{O}_{2}\right)$ - curve I. The difference between this ODMR spectrum and the spectrum measured from the reference sample (curve II) is shown by the curve III, which closely resembles that from $\mathrm{ZnO}: \mathrm{P}+\mathrm{N}_{2}$ (curve IV). This proves that the formation of the $\mathrm{Z}, \mathrm{T}$, and $D^{*}$ centers after annealing occurs independent of the gas ambient during RTA. 


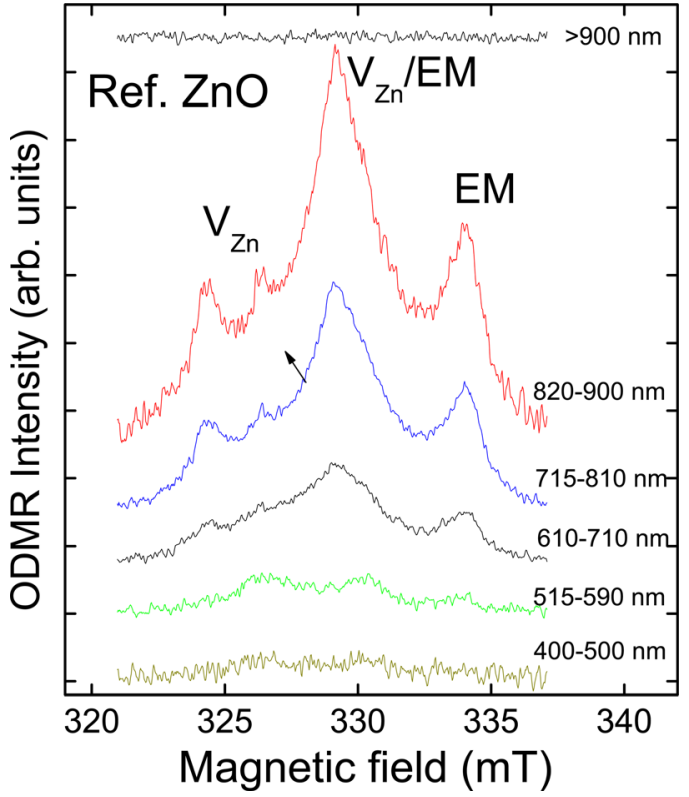

FIG. 5. (Color online) ODMR spectra from the reference $\mathrm{ZnO}$ measured with $\mathbf{B} \| \mathbf{c}$ within the specified spectral regions selected by choosing appropriate optical filters.

using appropriate optical filters. Since the overall ODMR intensity is rather low, samples with the highest intensity of a particular signal were chosen for this study. The corresponding results are presented in Figs. 5 and 6 for the reference and P-implanted samples, respectively. From Fig. 5 we see that the ODMR signals related to $\mathrm{V}_{\mathrm{Zn}}{ }^{-}$and $\mathrm{EM}$ are only detected within the limited spectral range of $1.38-2.1 \mathrm{eV}$ (i.e., $590-900 \mathrm{~nm}$ ) corresponding to the spin-dependent recombination process

$$
\mathrm{V}_{\mathrm{ZN}}^{-}+\mathrm{EM}^{0} \rightarrow \mathrm{V}_{\mathrm{ZN}}^{2-}+\mathrm{EM}^{+}
$$

as discussed in detail in Ref. 25. The $\mathrm{V}_{\mathrm{O}}{ }^{+}$and PD centers are also observed within the red spectral range. Based on the correlation between the spectral dependences of these signals (Fig. 6), it is reasonable to suggest that both defects are involved in the same spin-dependent process of electron transfer

$$
\mathrm{V}_{\mathrm{O}}^{+}+\mathrm{PD}^{0} \rightarrow \mathrm{V}_{\mathrm{O}}^{0}+\mathrm{PD}^{+} .
$$

It is hard to conclude whether the red PL itself or just a part of the recombination transitions giving rise to this emission arises from the process (4), as energy position of the oxygen vacancy currently remains under debates. ${ }^{5}$ As to the $\mathrm{Z}$ center, it participates in the yellow emission within the $1.55-$ $2.5 \mathrm{eV}(500-800 \mathrm{~nm})$ spectral range in the spin-dependent recombination involving the $\mathrm{D}^{*}$ center, consistent with the previous findings. ${ }^{29}$

\section{Defect origin and formation}

The results from the ODMR measurements provide important insight into the origin of the defects formed in $\mathrm{ZnO}$ single crystals upon $\mathrm{P}$ implantation and post-implantation

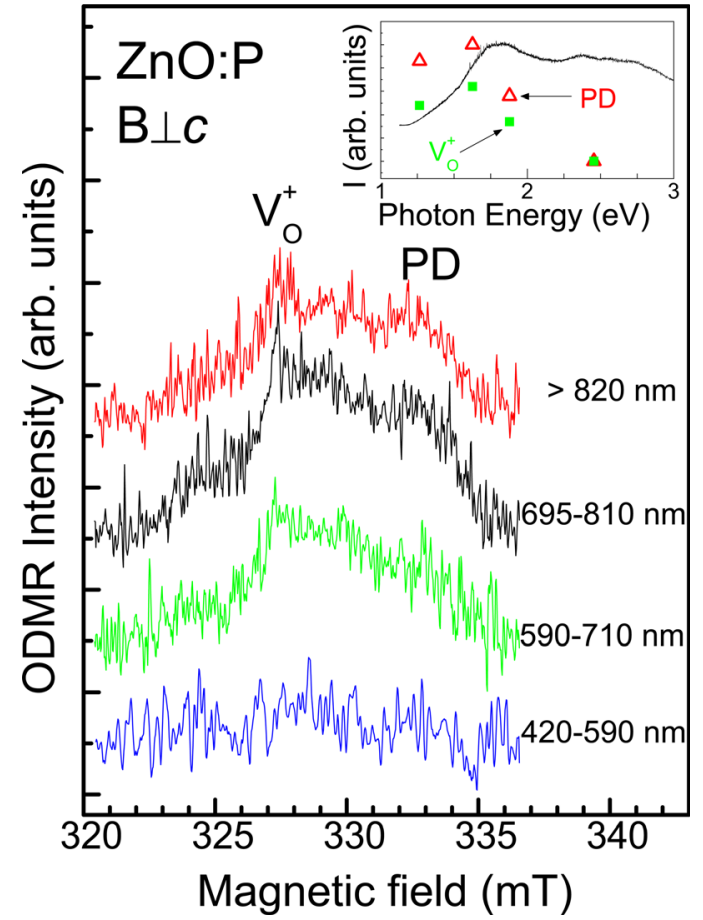

FIG. 6. (Color online) ODMR spectra from the P-implanted $\mathrm{ZnO}$ measured with $\mathbf{B} \| \mathbf{c}$ within the specified spectral windows selected by choosing appropriate optical filters. The inset shows the spectral dependences of the ODMR signals related to the $\mathrm{V}_{\mathrm{O}}^{+}$(filled squares) and PD (open triangles) centers.

annealing as summarized in Table II. First of all, two defects that are formed in $\mathrm{ZnO}: \mathrm{P}$ prior to annealing can unambiguously be identified as oxygen and zinc vacancies, in agreement with the results of the positron-annihilation studies. ${ }^{10}$ We note that even though the zinc vacancies were present in the investigated samples even prior to the implantation, their concentration increases after the treatment, as revealed by our complementary spin resonance measurements. This is probably not surprising as vacancies and interstitials are expected to be the primary defects created by the ion bombardment. Moreover, as $\mathrm{Zn}$ interstitials are known ${ }^{5}$ to be highly mobile even at room temperature, it is unlikely that they would be present in an isolated configuration. This accounts for the absence of the related signal in the measured ODMR spectra. Introduction of the oxygen vacancies could be detrimental for achieving p-type doping via ion implantation since $\mathrm{V}_{\mathrm{O}}$ is a deep donor in $\mathrm{ZnO}$ (Ref. 5) and, therefore, will compensate the implanted acceptors. This defect can be easily annealed out, however, by the post-implantation RTA. Zinc vacancies, on the other hand, may facilitate p-type doping as the

TABLE II. Summary of the defects detected by ODMR in the investigated $\mathrm{ZnO}$ materials.

\begin{tabular}{lcccccccc}
\hline \hline Samples & $\mathrm{V}^{-} \mathrm{Zn}^{-}$ & $\mathrm{V}^{-} \mathrm{Zn}^{-} / \mathrm{EM}$ & $\mathrm{EM}$ & $\mathrm{Vo}$ & $\mathrm{Z}$ & $\mathrm{T}$ & $\mathrm{D}^{*}$ & $\mathrm{PD}$ \\
\hline $\mathrm{ZnO} \mathrm{MBE}$ & & & & & $\sqrt{ }$ & $\sqrt{ }$ & $\sqrt{ }$ & \\
$\mathrm{Ref} . \mathrm{ZnO}$ & $\sqrt{ }$ & $\sqrt{ }$ & $\sqrt{ }$ & & & & & \\
$\mathrm{ZnO}: \mathrm{P}$ & $\sqrt{ }$ & & & $\sqrt{ }$ & & & & $\sqrt{ }$ \\
$\mathrm{ZnO}: \mathrm{P}+\mathrm{N}_{2}$ & & & & & $\sqrt{ }$ & $\sqrt{ }$ & $\sqrt{ }$ & \\
$\mathrm{ZnO}: \mathrm{P}+\mathrm{O}_{2}$ & $\sqrt{ }$ & $\sqrt{ }$ & $\sqrt{ }$ & & $\sqrt{ }$ & $\sqrt{ }$ & $\sqrt{ }$ & \\
\hline \hline
\end{tabular}


phosphorus-vacancy complex $\mathrm{P}_{\mathrm{Zn}}-2 \mathrm{~V}_{\mathrm{Zn}}$ is predicted $^{16}$ to introduce a shallow acceptor level at $\mathrm{E}_{\mathrm{v}}+150 \mathrm{meV}$.

Another defect created due to the P-implantation is the PD center. The defect acts as a donor, judging from the deduced g-values. However, the relative values of $g_{\|}$and $g_{\perp}$, i.e., $g_{\|}<g_{\perp}$, are rather unusual and seem to be detected only for deep donors such as $\mathrm{V}_{\mathrm{O}}{ }^{+}$(Ref. 20) and $\mathrm{V}_{\mathrm{O}^{-}} \mathrm{Li}_{\mathrm{Zn}}{ }^{31} \mathrm{On}$ the other hand, the reverse ordering $g_{\|}>g_{\perp}$ is typical for shallow (i.e., effective-mass like) donor signals in $\mathrm{ZnO}$, e.g., related to substitutional $\mathrm{In},{ }^{32} \mathrm{Ga},{ }^{33}$ and $\mathrm{H}$ (Ref. 34) atoms, as well as Zn (Ref. 24) and Li (Ref. 25) interstitials. We, therefore, suggest that the PD defect introduces a donor state that is not effective-mass like. Its formation is likely facilitated by the presence of phosphorous since the PD signal has not been reported previously in $\mathrm{ZnO}$ even after electron irradiation. According to the first-principle calculations,${ }^{14-16} \mathrm{sev}-$ eral phosphorous-related defects may introduce donor states in $\mathrm{ZnO}$. First of all, phosphorous is an amphoteric impurity and can either replace $\mathrm{O}$ or occupy a $\mathrm{Zn}$ lattice site. Whereas the substitutional $\mathrm{P}_{\mathrm{O}}$ is a deep acceptor, $\mathrm{P}_{\mathrm{Zn}}$ behaves as a triple donor $\mathrm{P}_{\mathrm{Zn}}$. Other examples of donor centers include $\mathrm{P}$ split interstitials, substitutional molecules $\left(\mathrm{P}_{2}\right)_{\mathrm{O}}$, as well as $\mathrm{P}_{\mathrm{Zn}}-\mathrm{V}_{\mathrm{Zn}}$ and $\mathrm{Zn}_{\mathrm{i}}-\mathrm{P}_{\mathrm{O}}$ complexes. According to the ODMR measurements performed on the post-implantation annealed $\mathrm{ZnO}$ (Fig. 2), the PD defect could be annealed out by RTA performed at $800^{\circ} \mathrm{C}$. Under the assumption that the PD center involves a $\mathrm{P}$ atom and is due to, e.g., the $\mathrm{Zn}_{\mathrm{i}}-\mathrm{P}_{\mathrm{O}}$ complex, the annealing of this defect could be attributed to breaking of bonding between the partners of the complex followed by diffusion of the mobile $\mathrm{Zn}_{\mathrm{i}}$ away from $\mathrm{P}_{\mathrm{O}}$. The calculations ${ }^{35}$ using density functional theory within the local density approximation predict a rather low binding energy for such complexes (e.g., $0.9 \mathrm{eV}$ for $\mathrm{Zn}_{\mathrm{i}}-\mathrm{N}_{\mathrm{O}}$ ), which makes them stable at room temperature but facilitates dissociation at elevated temperatures. The proposed model can also account for the observed activation by annealing of the deep acceptors responsible for the DAP1 emission at $3.156 \mathrm{eV}$ revealed by the PL measurements (Fig. 1). We note, however, that whether the phosphorous atom is directly involved in the PD center or merely promotes its formation, cannot be definitely concluded based on the currently available data, unfortunately, due to a lack of the resolved hyperfine structure related to phosphorous.

Let us now briefly discuss the possible chemical origin of the defects detected in the post-implantation annealed samples. The $\mathrm{Z}$ and $\mathrm{T}$ centers have first been observed by Aliev et $a l .{ }^{28}$ in nitrogen doped MBE-grown $\mathrm{ZnO}$. They have suggested that the $\mathrm{Z}$ center is a defect complex containing a $\mathrm{Zn}$ interstitial possibly in association with a perturbing defect such as a nitrogen atom at a nearby oxygen site $\left(\mathrm{Zn}_{\mathrm{i}}-\mathrm{N}_{\mathrm{o}}\right)$. However, Wang et al..$^{29}$ has questioned involvement of $\mathrm{N}$ as a partner of the $\mathrm{Z}$ center since the same defect was detected in undoped $\mathrm{ZnO}$ films grown by MBE. From Figs. 2 and 4, the $\mathrm{Z}$ center can also be formed in bulk $\mathrm{ZnO}$ after P-implantation and subsequent annealing in either $\mathrm{N}_{2}$ or $\mathrm{O}_{2}$ ambient. This suggests that it is not related to the acceptor dopant but rather involves native defects formed as a result of ion implantation. The same defects seem to be also favored during the MBE growth. In addition to $\mathrm{V}_{\mathrm{Zn}}$, native point defects that introduce acceptor states in $\mathrm{ZnO}$ include oxygen interstitial $\mathrm{O}_{\mathrm{i}}$ and oxygen antisite $\mathrm{O}_{\mathrm{Zn}} \cdot{ }^{36}$ Both of them have a very high formation energy ${ }^{36}$ which would prevent creation of these defects under thermally equilibrium growth conditions. However, they may be formed under nonequilibrium conditions such as under irradiation, ion implantation, or during the low temperature MBE. Theoretically predicted ${ }^{36}$ energy levels for these defects are at $\mathrm{E}_{\mathrm{v}}+0.72 \mathrm{eV}$ and $\mathrm{E}_{\mathrm{v}}+1.52 \mathrm{eV}$. Taking into account that the $\mathrm{Z}$ - signal is most pronounced in the samples that exhibit the yellow emission peaking at around $2.1-2.2 \mathrm{eV}$ (see Figs. 1 and 2 and also Ref. 29) the involvement of $\mathrm{O}_{\mathrm{i}}$ seems to be more probable. Of course, the $\mathrm{Z}$ center could also be a complex composed of several native defects or a native defect and a common contaminant. Further studies are required to clarify this issue and to provide the unambiguous defect identification.

\section{SUMMARY}

In summary, we have examined the effects of P implantation and post-implantation annealing on defect formation in $\mathrm{ZnO}$ single crystal by using the PL and ODMR techniques. From the PL measurements, combined effects of the implantation and annealing lead to appearance of the new PL band peaking at $\sim 3.156$, likely due to DAP recombination. The formation of the involved deep acceptor is concluded to be facilitated by the presence of phosphorous as the PL emission was only detected in the P-containing $\mathrm{ZnO}$. According to the ODMR measurements, the defects created by the ion implantation include oxygen and zinc vacancies as a well as the deep PD donor. The PD defect may involve a P atom, e.g., within the $\mathrm{Zn}_{\mathrm{i}}-\mathrm{P}_{\mathrm{O}}$ complex, as it has only been detected in the $\mathrm{P}$-containing $\mathrm{ZnO}$. The $\mathrm{V}_{\mathrm{O}}$ and PD centers are found to exhibit low thermal stability and are readily annealed out by RTA performed at $800^{\circ} \mathrm{C}$. Such treatment, on the other hand, is shown to promote formation of a new set of defects such as the $\mathrm{Z}, \mathrm{T}$, and $\mathrm{D}^{*}$ centers presumably associated with native defects or related complexes. Based on the measured spectral dependences of the ODMR signals, the $\mathrm{Z}, \mathrm{T}$, and $\mathrm{D}^{*}$ centers are shown to be involved in the yellow emission peaking at $2.05 \mathrm{eV}$, whereas the $\mathrm{V}_{\mathrm{O}}, \mathrm{V}_{\mathrm{Zn}}$ and PD centers participate in spin-dependent recombination processes related to the red emissions within the $1.38-2.1 \mathrm{eV}$ spectral range. It is also demonstrated that although both types of vacancies take part in the radiative transitions within the same spectral range, they are involved in different recombination processes. Our results, therefore, prove that several "red" emissions of different origin exist in $\mathrm{ZnO}$ and underline the danger of claiming formation of a certain defect solely based on PL studies.

\section{ACKNOWLEDGMENTS}

Financial support by the Swedish Research Council (Grant No. 621-2010-3971) is greatly appreciated. X.J.W. would also like to acknowledge the support from National Basic Research Program of China (contract No. 2011CB925604).

${ }^{1}$ For a recent review, see, e.g. S. J. Pearton, F. Ren, Y. L. Wang, B. H. Chu, K. H. Chen, C. Y. Chang, W. Lim, J. Lin, and D. P. Norton, Prog. Mater. Sci. 55, 1 (2010). 
${ }^{2}$ For a recent review, see V. Avrutin, N. Izyumskaya, U. Ozgur, D. J. Silversmith, and H. Morkoc, P. IEEE 98, 1288 (2010).

${ }^{3}$ For a recent review, see S. J. Pearton, D. P. Norton, M. P. Ivill, A. F. Hebard, J. M. Zavada, W. M. Chen, and I. A. Buyanova, IEEE Trans. Electron Devices 54, 1040 (2007).

${ }^{4}$ For a recent review, see C. Klingshirn, Phys. Status Solidi A 244, 3027 (2007).

${ }^{5}$ For a recent review, see A. Janotti and C. G. Van de Walle, Rep. Prog. Phys. 72, 126501 (2009).

${ }^{6}$ K. K. Kim, H. S. Kim, D. K. Hwang, J. H. Lim, and S. J. Park, Appl. Phys. Lett. 83, 63 (2003).

${ }^{7}$ D. K. Hwang, M. S. Oh, Y. S. Choi, and S. J. Park, Appl. Phys. Lett. 92, 161109 (2008).

${ }^{8}$ F. X. Xiu, Z. Yang, L. J. Mandalapu, J. L. Liu, and W. P. Beyermann, Appl. Phys. Lett. 88, 052106 (2006).

${ }^{9}$ A. Allenic, W. Guo, Y. B. Chen, Y. Che, Z. D. Hu, B. Liu, and X. Q. Pan, J. Phys. D: Appl. Phys. 41, 025103 (2008).

${ }^{10}$ F. G. Chen, Z. Z. Ye, W. Z. Xu, B. H. Zhao, L. P. Zhu, and J. G. Lv, J. Cryst. Growth 281, 458 (2005).

${ }^{11}$ Y. T. Shih, J. F. Chien, M. J. Chen, J. R. Yang, and M. Shiojiri, J. Electrochem. Soc. 158, H516 (2011).

${ }^{12}$ Y. W. Heo, S. J. Park, K. Ip, S. J. Pearton, and D. P. Norton, Appl. Phys. Lett. 83, 1128 (2003)

${ }^{13}$ M. Brandt, H. von Wenckstern, H. Schmidt, A. Rahm, G. Biehne, G. Benndorf, H. Hochmuth, M. Lorenz, C. Meinecke, and T. Butz, J. Appl. Phys. 104, 013708 (2008)

${ }^{14}$ W.-J. Lee, J. Kang, and K. J. Chang, Phys. Rev. B 66, 073202 (2002).

${ }^{15}$ C. H. Park, S. B. Zhang, and S.-H. Wei, Phys. Rev. B 73, 024117 (2006).

${ }^{16}$ P. Li, S. H. Deng, and J. Huang, Appl. Phys. Lett. 99, 111902 (2011).

${ }^{17}$ V. Vaithianathan, S. Hishita, J. Y. Park, and S. S. Kim, J. Appl. Phys. 102, 086107 (2007).

${ }^{18}$ Z. Q. Chen, A. Kawasuso, Y. Xu, H. Naramoto, X. L. Yuan, T. Sekiguchi, R. Suzuki, and T. Ohdaira, J. Appl. Phys. 97, 013528 (2005).
${ }^{19}$ For a recent review, see, e.g., M. D. McCluskey and S. J. Jokela, J. Appl. Phys. 106, 071101 (2009).

${ }^{20}$ L. S. Vlasenko and G. D. Watkins, Phys. Rev. B 71, 125210 (2005).

${ }^{21}$ For a review, see S. O. Kucheyev, J. S. Williams, and C. Jagadish, Vacuum 73, 93 (2004).

${ }^{22}$ F. Reuss, C. Kirchner, Th. Gruber, R. Kling, S. Maschek, W. Limmer, A. Waag, and P. Ziemann, J. Appl. Phys. 95, 3385 (2004).

${ }^{23}$ W. M. Chen, Thin Solid Films 364, 45 (2000).

${ }^{24}$ L. S. Vlasenko and G. D. Watkins, Phys. Rev. B 72, 035203 (2005).

${ }^{25}$ X. J. Wang, L. S. Vlasenko, S. J. Pearton, W. M. Chen, and I. A. Buyanova, J. Phys. D: Appl. Phys. 42, 175411 (2009).

${ }^{26}$ B. K. Meyer, H. Alves, D. M. Hofmann, W. Kriegseis, D. Forster, F. Bertram, J. Christen, A. Hoffmann, M. Strassburg, M. Dworzak, U. Haboeck, and A. V. Rodina, Phys. Status Solidi B 241, 231 (2004).

${ }^{27}$ J. M. Smith and W. E. Vehse, Phys. Lett. A 31, 147 (1970).

${ }^{28}$ G. N. Aliev, S. J. Bingham, D. Wolverson, J. J. Davies, H. Makino, H. J. Ko, and T. Yao, Phys. Rev. B 70, 115206 (2004).

${ }^{29}$ X. J. Wang, I. A. Buyanova, W. M. Chen, C. J. Pan, and C. W. Tu, J. Appl. Phys. 103, 023712 (2008).

${ }^{30} \mathrm{~A}$ weak background Gaussian signal with g-value of $\sim 1.985$ of unknown origin was also included in the simulated spectra, to improve agreement with the experimental data.

${ }^{31}$ K. Tarkpea, A. Ots, and V. Nikitenko, J. Phys. Chem. Solids 55, 1353 (1994).

${ }^{32}$ B. Block, A. Harve, and R. T. Cox, Phys. Rev. B 25, 6049 (1982).

${ }^{33}$ N. Y. Garces, N. Giles, L. E. Halliburton, G. Cantwell, D. B. Eason, D. C. Reynolds, and D. C. Look, Appl. Phys. Lett. 80, 1334 (2002).

${ }^{34}$ D. M. Hofmann, A. Hofstaetter, F. Leiter, H. Zhou, F. Henecker, and B. K. Meyer, Phys. Rev. Lett. 88, 045504 (2002).

${ }^{35}$ D. C. Look, G. C. Farlow, P. Reunchan, S. Limpijumnong, S. B. Zhang, and K. Nordlund, Phys. Rev. Lett. 95, 225502 (2005).

${ }^{36}$ A. Janotti and C. G. Van de Walle, Phys. Rev. B 76, 165202 (2007). 